\title{
Cost effectiveness of the NHS breast screening programme: life table model
}

In the online version of this Research paper by Paul D P Pharoah and colleagues (BMJ 2013;346:f2618, doi:10.1136/bmj.f2618) there are some numerical errors in the bottom half of table 1. 


\section{Table}

$\overline{\text { Table } 1 \text { [ [CORRECTED VERSION] Comparison of outcomes between screened and unscreened cohorts, under different screening conditions }}$ Screened cohort Unscreened cohort Difference (interquartile range)†

Population $\mathrm{n}=364$ 500, screening uptake $75 \%$

\begin{tabular}{|c|c|c|c|}
\hline Breast cancer cases & 29111 & 26389 & 2722 (2153 to 2829$)$ \\
\hline Breast cancer deaths & 8742 & 10263 & $-1521(-1075$ to -1600$)$ \\
\hline Deaths from other causes & 208449 & 207720 & 729 (546 to 784$)$ \\
\hline Deaths from all causes & 217192 & 217983 & $-792(-525$ to -823$)$ \\
\hline Person years of survival ${ }^{*}$ & 6630068 & 6623161 & 6907 (4798 to 7328$)$ \\
\hline Person years of survival after diagnosis of breast cancer* & 179847 & 138901 & 40946 (36 194 to 43710$)$ \\
\hline Quality adjusted life years* $^{*}$ & 5330702 & 5328662 & 2040 (847 to 2974 ) \\
\hline Cost $(£ m)^{\star}$ & 179 & 136 & $42.5(36.8$ to 49.9$)$ \\
\hline \multicolumn{4}{|l|}{ Population $n=10000$, screening uptake $100 \%$} \\
\hline Breast cancer cases & 824 & 724 & 100 (79 to 103$)$ \\
\hline Breast cancer deaths & 226 & 282 & $-55 \S(-39$ to -59$)$ \\
\hline Deaths from other causes & 5725 & 5699 & $27 \S(20$ to 29$)$ \\
\hline Death from all causes & 5951 & 5980 & $-29(-19$ to -31$)$ \\
\hline Person years of survival ${ }^{*}$ & 181958 & 181705 & 253 (176 to 268$)$ \\
\hline Person years of survival after diagnosis of breast cancer* & 5309 & 3811 & 1498 (1324 to 1599$)$ \\
\hline Quality adjusted life years ${ }^{*}$ & 146266 & 146191 & 75 (31 to 109$)$ \\
\hline Cost $(£ m)^{*}$ & 5.3 & 3.7 & $1.6(1.3$ to 1.8$)$ \\
\hline
\end{tabular}

*Discounted at $3.5 \%$ per year.

†Interquartile range for outputs from probabilistic sensitivity analysis.

$\S$ Numbers do not add because of rounding errors. 